\title{
Lymphocytic meningitis, a rare feature of hashimoto's thyroiditis: a case report
}

\begin{abstract}
Background: The neurological features of Hashimoto's thyroiditis are several. Aseptic meningitis was rarely reported.

Case report: A 32-year-old woman was admitted to hospital with headache, fever, dizziness and vomiting. Cerebrospinal fluid analyses concluded to a lymphocytic meningitis. Bacterial and viral screening was negative. Other laboratory data showed hyperthyroïdism with high level of antithyroïd antibodies. Thyroid ultrasound was suggestive of thyroiditis.
\end{abstract}

Conclusion: Lymphocytic meningitis may be the first feature of Hashimoto's thyroiditis.

Keywords: hashimoto's thyroïditis, lympocytic meningitis, hashimoto's encephalopathy
Volume 4 Issue 4 - 2017

\section{Tayeb Z, CherifY, Mrouki M, Ben Dahmen F, Abdallah $M$ \\ Internal Medicine Department, Tunis El Manar University, Tunisia}

Correspondence: CherifY,Tunis El Manar University, Internal Medicine department, Medical faculty of Tunis, 1007, TunisTunisia, Email cherifyousra20II@gmail.com

Received: March 31, 2017 | Published: May 09, 2017

\section{Introduction}

Hashimoto's thyroïditis (HT) is a specific autoimmune disease. Transient hyperthyroïdism is observed in 5 to $10 \%$ of the patients..$^{1-3}$ The diagnosis is often made when hypothyroïdism is established. Several neurological features were described in littérature. ${ }^{1,4}$ Nonetheless, aseptic and lymphocytic meningitis is un commun. ${ }^{4} \mathrm{We}$ report an unusual case of a woman with concomitant lymphocytic meningitis and HT.

\section{Case report}

A previously healthy 32-year-old woman was admitted to hospital with fever and headache. Her previous family and personal history was unremarkable. She had a 3 days history of headache, dizziness, nausea and vomiting. She also complained about photophobia and sonophobia.

Physical examination revealed fever at $38.5^{\circ} \mathrm{C}$, heart beat rate at 88 per minute, blood pressure at $100 / 70 \mathrm{mmHg}$, painless thyroid goiter. Neurological examination showed a meningism with no deficits.

In laboratory, full blood count, $\mathrm{C}$ reactive protein, urea, creatinine, electrolytes, liver function tests were normal. Thyroid function tests revealed a hyperthyroid state with reduced serum levels of thyroidstimulating hormone (TSH $0.001 \mathrm{mIU} / \mathrm{ml}$; normal $0.40-4.0 \mathrm{mIU} / \mathrm{ml}$ ) and increased free T4 levels (35pmol/L; normal 10.3-24.4pmol/1).

Furthemore, Lumbar puncture revealed a cell count of 190/ $\mathrm{mm}^{3}$ celle (mostly lymphocytes: $90 \%$ ), low glucose and increased protein $(750 \mathrm{mg} / \mathrm{dl})$ strongly suggestive of meningitis. The culture of cerebrospinal fluid as well as blood cultures were normal. High levels of anti-thyroid peroxidase antibodies were present $(1365 \mathrm{IU} / \mathrm{ml}$ normal $<70 \mathrm{IU} / \mathrm{ml})$. Cerebral computed tomography was normal. Thyroïd ultrasound was suggestive of thyroiditis. Screening espacially of herpes simplex virus, varicella zona virus, cytomegalovirus,, Epstein barr virus and human immunodificiency virus was negative.

The diagnosis of HT associated to a lymphocytic meningitis was made. The patient was treated with Thiamazole (20mg daily) and beta blocker (40mg daily). Her neurological features improved within few days and she was discharged. Two years later, neurological relapse did not accur.

\section{Discussion}

HT is the most common thyroïd disease. ${ }^{1,2}$ It is more 8 times more frequent in women than men. ${ }^{1,2}$ Hashimoto's encephalopathy is a scarce syndrome associated with HT. The first case diagnosed with Hashimoto's encephalopathy was reported in 1966. ${ }^{5,6}$ The clinical findings are various ranging from behavior changes, cognitive impairement, seizures, pyramidal syndrome, involuntary movements, confusion, stroke events, memory loss, coma and psychosis. ${ }^{6}$ Our patient has none of these neurological manifestations. She presented with HT associated to a lymphocytic meningitis. In fact, high protein levels are found in up to $85 \%$ of patients diagnosed with an Hashimoto's encephalopathy., ${ }^{4-8}$

A antithyroid peroxidase antibody is the most found antibody. ${ }^{8}$ Besides, abnormal levels of thyroid antibodies can be found in cerebrospinal fluid in case of Hashimoto's encephalopathy. ${ }^{6,10}$ In deed, High fever and hyperthyroidism made it difficult to distinguish this condition from viral encephalitis or thyroid storm, like in our case. In the litterature, only one case was reported describing a patient with febrile Hashimoto's encephalopathy and thyrotoxicosis. ${ }^{9}$

Hashimoto's encephalopathy respondes well to glucocorticoids and other immunosuppressive drugs. ${ }^{4,6,10,11}$

Neurological and psychiatric features associated to hyperthyroidism usually improves when the disease is rapidly contolled. A late diagnosis or inadaquate management of the disease can lead to irreversible psychiatric and neurological sequelae. ${ }^{10,11}$ Our patient responded well only to antithyroid drug and had no relapse of meningitis within 2 years.

To our knowldge, we reported the first case of febrile lymphocytic meningitis associated with HT. Therefore, we should screen antithyroid antibodies in cases of meningoencephalopathy. HT may be thereby, misdiagnosed and late treated and should be cautiously investigated. 


\section{Acknowledgements}

None.

\section{Conflicts of interest}

The author declares there is no conflict of interest.

\section{References}

1. Vanderpump MP. The epidemiology of thyroid disease. Br Med Bull. 2011;99:39-51.

2. Caturegli P, De Remigis A, Rose NR. Hashimoto thyroiditis: clinical and diagnostic criteria. Autoimmun Rev. 2014;13(4-5):391-397.

3. Caturegli P, De Remigis A, Chuang K, et al. Hashimoto's thyroiditis: celebrating the centennial through the lens of the Johns Hopkins hospital surgical pathology records. Thyroid. 2013;23(2):142-150.

4. Endres D, Perlov E, Stich O, et al. Steroid-responsive encephalopathy associated with autoimmune thyroiditis. Arch Neurol. 2006;16:184.
5. Mocellin R, Walterfang M, Velakoulis D. Hashimoto's disease and encephalopathy. Lancet. 1966;21(10):799-811.

6. Afshari M, Afshari ZS, Schuele SU. Pearls \& oy-sters: Hashimoto encephalopathy. Neurology. 2012;78(22):134e -137e.

7. Zhou JY, Xu B, Lopes J, et al. Hashimoto encephalopathy: literature review. Acta Neurol Scand. 2017;135(3):285-290.

8. Gul Mert G, Horoz OO, Herguner MO. Hashimoto's encephalopathy: four cases and review of literature. Int J Neurosci. 2014;124(4):302306.

9. Lu T, Zhou Z, Wu A, et al. Febrile Hashimoto's encephalopathy associated with Hashitoxicosis. Acta Neurol Belg. 2015;115(4):811-813.

10. Endres D, Perlov E, Stich O, et al. Steroid responsive encephalopathy associated with autoimmune thyroiditis (SREAT) or Hashimoto's encephalopathy: a case and review. Psychosomatics. 2011;16:184.

11. Olmez I, Moses H, Sriram S, et al. Diagnostic and therapeutic aspects of Hashimoto's encephalopathy. J Neroli Sci. 2013;331(1-2):67-71. 